\title{
КОМП'ЮТЕРНЕ МОДЕЛЮВАННЯ ПРОЦЕСІВ КУВАННЯ ТОВСТОСТІННИХ ТРУБ БЕЗ ОПРАВКИ
}

\section{О. С. Марков, О. В. Герасименко}

Донбаська державна машинобудівна академія

вул. Академічна, 72, г. Краматорськ, 84313, Україна.

E-mail: oleg.markov.omd@gmail.com; mto@dgma.donetsk.ua

Розроблено новий спосіб кування товстостінних труб, який полягає в деформуванні пустотілої заготовки без використання ковальської оправки. Розроблено методику проведення теоретичних досліджень методом скінчених елементів (МСE). Методика призначена для визначення теплового, деформованого стану та формозміни заготовки при куванні труб без використання ковальської оправки. Змінними параметрами був внутрішній діаметр пустотілої заготовки, який варіювався в інтервалі 0,$30 ; 0,55 ; 0,80$. На основі скінчено-елементного моделювання були встановлені: розподіл температур і логарифмічних деформацій в об'ємі труби після протягування без використання оправки. Визначався діаметр отвору труби, який утворюється при протягуванні даним способом. Встановлювалися залежності інтенсивності подовження і потовщення стінки труби. Був розроблений спеціальний показник для оцінювання інтенсивності подовження труби. Було визначено, що при збільшені внутрішнього діаметру подовження труби збільшується та знижується інтенсивність зменшення отвору. Загальною залежністю змодельованих схем протягування $є$ те, що величина подовження пустотілої заготовки несуттєво змінюється для різних ступенів обтискань при сталих відносних розмірах труби. Це дозволило встановити рекомендовану подачу для збільшення подовження пустотілої поковки та зменшення ступеня закриття отвору. Раціональна подача повинна складати $(0,05 \ldots 0,15) \mathrm{D}$. Одержані результати дозволили визначили раціональні геометричні параметри трубної заготовки до деформування без використання оправки. За результатами комп'ютерного моделювання МСЕ встановлено, що протягування трубних заготовок без використання ковальської оправки цілком можливе. Цей спосіб розширює можливості технологічних процесів виготовлення трубних заготовок куванням. Практичним аспектом використання результатів моделювання є вдосконалення техпроцесу протягування труб з внутрішнім діаметром $<300$ мм, коли застосування оправки неможливе.

Ключові слова: товстостінна труба, протягування без оправки, кування, заковування отвору, подовження.

\section{КОМПЬЮТЕРНОЕ МОДЕЛИРОВАНИЕ ПРОЦЕССОВ КОВКИ ТОЛСТОСТЕННЫХ ТРУБ БЕЗ ОПРАВКИ}

\section{О. Е. Марков, А. В. Герасименко}

Донбасская государственная машиностроительная академия

ул. Академическая, 72, г. Краматорск, 84313, Украина.

E-mail: oleg.markov.omd@gmail.com; mto@dgma.donetsk.ua

Разработан новый способ протяжки толстостенных труб, который заключается в ковке пустотелой заготовки без использования кузнечной оправки. Разработана методика проведения теоретических исследований методом конечных элементов (МКЭ). Методика предназначена для определения теплового, деформированного состояния и формоизменения заготовки при ковке труб без использования оправки. Переменными параметрами были внутренний диаметр пустотелой заготовки, который варьировался в интервале $0.30 ; 0.55 ; 0.80$. На основе конечно-элементного моделирования были установлены: распределение температур и интенсивности логарифмических деформаций в объеме трубы после протяжки без использования оправки. Определялся диаметр отверстия трубы, который образуется при протяжке данным способом. Устанавливались зависимости интенсивности удлинения и утолщения стенки трубы. Был разработан специальный показатель для оценки интенсивности удлинения трубы. Было определено, что при увеличении внутреннего диаметра удлинение трубы увеличивается и снижается интенсивность заковки отверстия. Общей зависимостью смоделированных схем протяжки является то, что величина удлинения пустотелой заготовки несущественно меняется для различных степеней обжатий при постоянных относительных размерах трубы. Это позволило установить рекомендованную подачу для увеличения удлинения пустотелой поковки и уменьшения степени закрытия отверстия. Рациональная подача должна составлять $(0,05 \ldots 0,15) \mathrm{D}$. Полученные результаты позволили определили оптимальные геометрические параметры трубной заготовки до деформирования без использования оправки. По результатам компьютерного моделирования МКЭ установлено, что протяжка трубных заготовок без использования кузнечной оправки возможна. Этот способ расширяет возможности технологических процессов изготовления трубных заготовок ковкой. Практическим аспектом использования результатов моделирования является совершенствование техпроцесса протягивания труб с внутренним диаметром $<300$ мм, когда применение оправки невозможно.

Ключевые слова: толстостенная труба, протяжка без оправки, ковка, заковывание отверстия, интенсивность удлинения.

АКТУАЛЬНІСТЬ РОБОТИ. Пріоритетним напрямком розвитку важкого машинобудування є підвищення якості деталей відповідального призначення для підвищення їх експлуатаційних характеристик і зниження витрат на їх виробництво. На сьогоднішній день існує затребуваність в підвищенні якості і зниженні витрат на виготовлення великогаба- ритних деталей відповідального призначення, які застосовуються в енергетиці, важкому машинобудуванні та ін. До цих деталей належать товстостінні труби. Ці поковки необхідно виготовляти куванням на оправці. Однак, товстостінні труби виготовляються 3 суцільних валів із використанням операції висвердлювання отвору [1]. В результаті збільшу- 
ється час механічної обробки, підвищуються витрати металу і відбувається перерізання волокна. Це пов'язано 3 тим, що при довжині труб більш 4000 мм та діаметрі отвору менше 300 мм використання оправки під час протягування неможливо [2]. Тому проблема виготовлення заготовок товстостінних труб на сьогодні $\epsilon$ актуальною, яка потребує всебічного аналізу та удосконалення [3].

Зниження собівартості виготовлення труб потребує удосконалення процесів кування. Удосконалення способу можливе після аналізу останніх публікацій $з$ цього питання.

3 використанням методу верхньої оцінки Yunjian Wu i співавторами запропонована модель для визначення осьової деформації металу в процесі радіального кування, що дозволяє прогнозувати силу кування в залежності від величини обтискання [4]. Авторами встановлено вплив осьової подачі заготовки та їі обтискання на викривлення профілю в меридіональної площині поковки. Отримана модель не дозволяє визначити радіальну течію металу в процесі деформації, що вимагає рішення задачі в тривимірній постановці.

H. W. Sizek в своїй роботі [5] запропонував нову технологію виготовлення складнопрофільних пустотілих поковок, в якій частина поковки нагрівають i штампують в закритих штампах. Поєднання осьової сили і використання закритих штампів гарантує, що матеріал тече в центральних частина. Після висадки ступеневого контуру вісь кінців формується на оправці з водяним охолодженням

У своєму дослідженні А. Ghaei й ін. MCE провели моделювання процесу радіальної кування труб без оправки [6]. Результати цього дослідження дозволили встановити, що процес радіального кування без оправки особливо ефективний при невеликій осьовій подачі. Осьові розтягуючі напруження на внутрішній поверхні труби можуть привести до утворення кільцевих тріщин в кованій трубі. При куванні без оправки збільшення осьової подачі збільшує максимальне осьове навантаження, яке може привести до появи тріщин. При куванні без оправки збільшуються залишкові напруження в порівнянні 3 куванням на оправці.

B результаті досліджень Lixia Fan i співавторів була розроблена скінчено-елементна 3D-модель процесу радіальної кування пустотілих заготовок на оправці і проведено всебічний аналіз деформованого стану металу в процесі кування [7]. Показана ефективність процесу всебічного обтискання пустотілої заготовки на оправці. Встановлено, що кут кантування заготовки не має значного впливу на формозміни поковки [8]. Однак отримання куванням заготовок з малим внутрішнім діаметром із застосуванням оправки неможливо внаслідок малого діаметра каналу при значній його довжині.

Аналіз літератури дозволив визначити, що проблема виготовлення товстостінних труб на сьогодні остаточно не вирішена. Найпрогресивнішими методами визначені способи протягування без використання оправки. Але НДС та формозмінення отвору труби у процесі протягування без використання оправки не встановлені [9]. Тому потрібно удосконалити та дослідити процеси протягування труб без використання оправки. Розробка нових техпроцесів кування труб без використання ковальської оправки потребує проведення комплексного моделювання i розробки рекомендацій для їх реалізації [10].

Мета роботи - дослідження нового процесу кування товстостінних труб без використання ковальської оправки для зменшення часу та витрат металу при механічній обробці труб відповідального призначення. Для досягнення зазначеної мети були поставлені наступні задачі:

- встановити тепловий стан заготовки при куванні труб без оправки;

- визначити вплив внутрішнього діаметру трубної заготовки на змінення довжини труби при куванні без оправки;

- визначити закономірності зміни відносної товщини стінки трубної заготовки при куванні без використання оправки.

МАТЕРІАЛ І РЕЗУЛЬТАТИ ДОСЛІДЖЕНЬ. Дослідження формозміни і параметрів НДС заготовки в процесі кування без оправки проводилося МСЕ. У зв'язку з цим була розроблена методика теоретичних досліджень на основі чисельних методів дослідження. Як матеріал заготовки була обрана конструкційна сталь 34ХНМ (з якої виготовляються подібні деталі на виробництві), температурний інтервал кування для цієї сталі $1200 \ldots 800^{\circ} \mathrm{C}$. Густина при кімнатній температурі становила 7840 кг $/ \mathrm{m}^{3}$; модуль Юнга 2•105 МПа; коефіцієнт Пуассона 0,3. Вихідні дані для розрахунку: початкова температура $\mathrm{t}=1200^{\circ} \mathrm{C}$; швидкість деформування $v=40 \mathrm{Mm} / \mathrm{c}$; початковий зовнішній діаметр пустотілої заготовки $\mathrm{D}=1000$ мм. Співвідношення зовнішнього та внутрішнього діаметру отвору $\mathrm{d} 0 / \mathrm{D}=0,3 ; 0,55 ; 0,8$. Схема процесу деформування наведена на рис. 1.

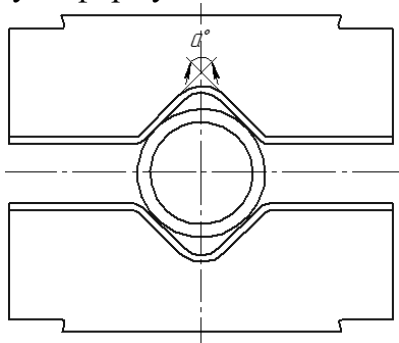

Рисунок 1 - Розрахункова схема кування без використання ковальської оправки

У досліджені використовувалися циліндричні сталеві пустотілі моделі. Зовнішній діаметр заготовок $\mathrm{D}=1000$ мм, а діаметр внутрішнього отвору варіюється в діапазоні d0 = 800 мм; 550 мм; 300 мм; висота заготовок становила Н1 $=480 ; 330 ; 288$ мм. Варіювання діаметрів отворів і висот дозволяє забезпечити постійний об'єм заготовки для адекватного порівняння отриманих результатів. Для утримання заготовки при куванні призначалася цапфа, тому заготовка мала глухе дно.

Був удосконалений техпроцес виготовлення пустотілих заготовок без оправки, яка полягає у прошиванні заготовки і їі протягування вирізними бойками, причому заготовка має цапфу для утримування маніпулятором, а остаточне кування поковок відбувається без оправки всередині. Використання цього способу і спеціальних механічних режимів кування 
дозволяє виготовляти суцільно ковані пустотілі заготовки без оправки. Однак на сьогоднішній день цей спосіб залишається недослідженим теоретично і експериментально, більш того, відсутні рекомендації для промислового впровадження даного способу.

Формозміна пустотілих заготовок в процесі кування без оправки залежить від параметрів НДС. НДС, в свою чергу, залежить від геометрії інструмента і режимів кування. Процес кування без оправки пустотілих заготовок характеризується збільшенням товщини стінки поковки. Тому для встановлення механізму заковування отвору необхідно провес-
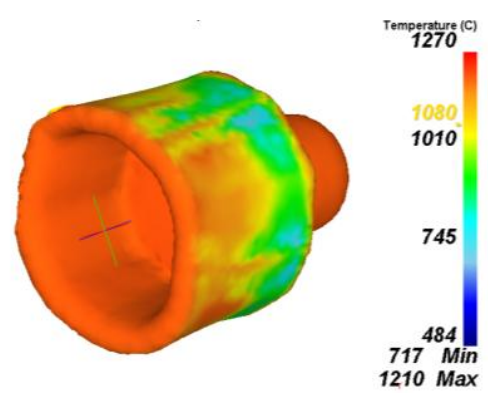

a)

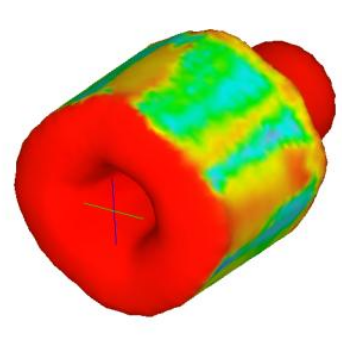

б) ти дослідження впливу кування пустотілих заготовок вирізними бойками.

Для точного встановлення ДС слід визначити розподіл температур поковки при куванні. Розподіл температур після деформування дозволить визначити потрібну кількість підігрівань. Розподіл температур у заготовці визначався МСЕ.

Аналіз результатів розподілу температур в об'ємі заготовки після обтискання на $20 \%$ дозволив встановити, що градієнт температур не виходить за межі температурного інтервалу кування для даних співвідношень розмірів поковки (рис. 2).

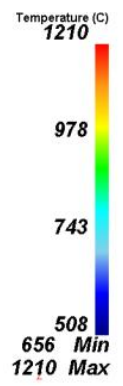

1210 Max

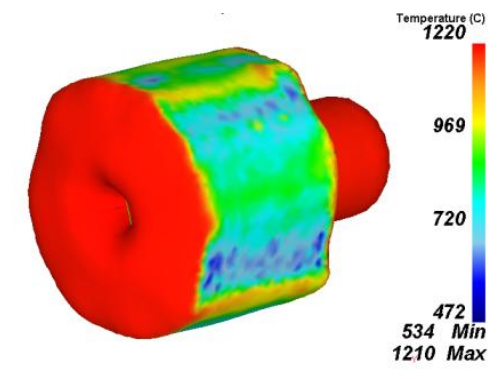

B)

Рисунок 2 - Розподіл температур для різних діаметрів отворів заготовок (d0 / D): a - 0,80; б - 0,55; c - 0,30

Середній перепад температур в об'єми поковки становить $350^{\circ} \mathrm{C}$. Отримані результати дозволили встановити, що одного підігріву достатньо для реалізації процесу кування пустотілих заготовок без оправки. Отримані результати пояснюються відсутністю відводу тепла на оправку, яка в базовому технологічному процесі охолоджується водою. Це дозволяє розширити технологічні можливості пропроцесу кування пустотілих заготовок за рахунок збільшення кількості обтискань і проходів за одне нагрівання заготовки.

При протягуванні відбувається зменшення площі поперечного перерізу і збільшення довжини загото- вки. Ця умова має зберігається і для протягування пустотілих заготовок. Отже, при збільшенні початкової площі поперечного перерізу заготовки (для малих співвідношень d0 / D) і при однаковій ступені деформації заготовки довжина заготовки після протягування буде більше (виконання закону сталості об'єму в процесі пластичної деформації).

Моделювання процесу кування пустотілих заготовок без оправки вирізними бойками з кутом $120^{\circ}$ та подачею 0,5 від діаметра заготовки (рис. 3) підтвердило припущення про те, що в результаті деформування вирізними бойками відбувається заковування отвору заготовки (рис. 4).

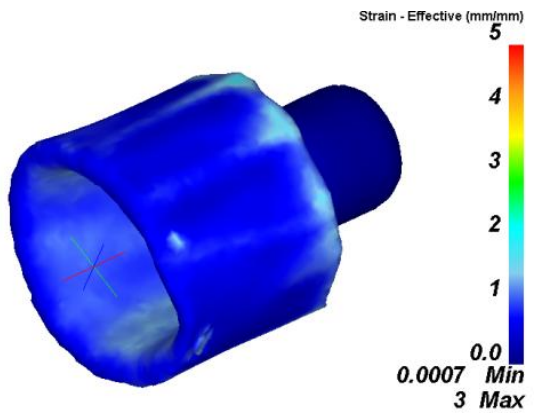

a)

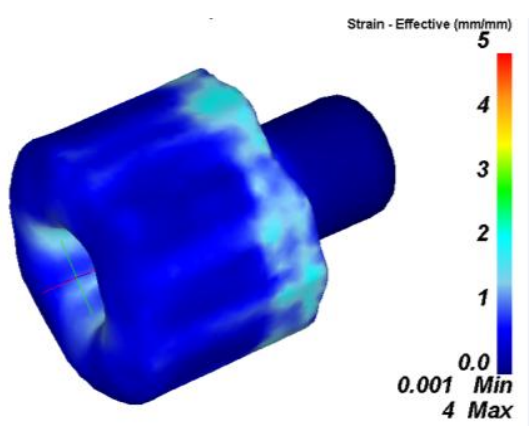

б)

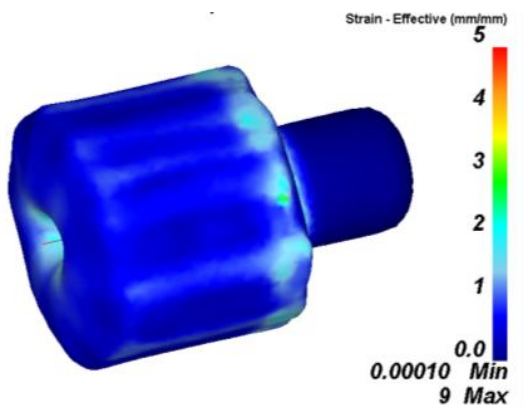

B)

Рисунок 3- Розподіл деформацій для різних діаметрів отвору заготовок (d0/D): a - 0,80; б - 0,55; c - 0,30

При цьому, величина заковування отвору складається 3 двох складових: зменшення діаметра отвору за рахунок зменшення зовнішнього діаметра заготовки, а також за рахунок збільшення товщини стінки пустотілої заготовки.

За умови, що заготовки обтискаються на однаковий ступінь деформації $(\varepsilon)$, з постійним початковим діаметром ( $\mathrm{D}=1000$ мм), ступінь заковування отво- ру визначається збільшенням товщини стінки. У результаті теоретичних досліджень процесу протягування без оправки вирізними бойками без скосів встановлено вплив відносного діаметра отвору заготовки (d0 / D) на заковування отвору (рис. 4) і відносне подовження заготовки (рис. 5). 


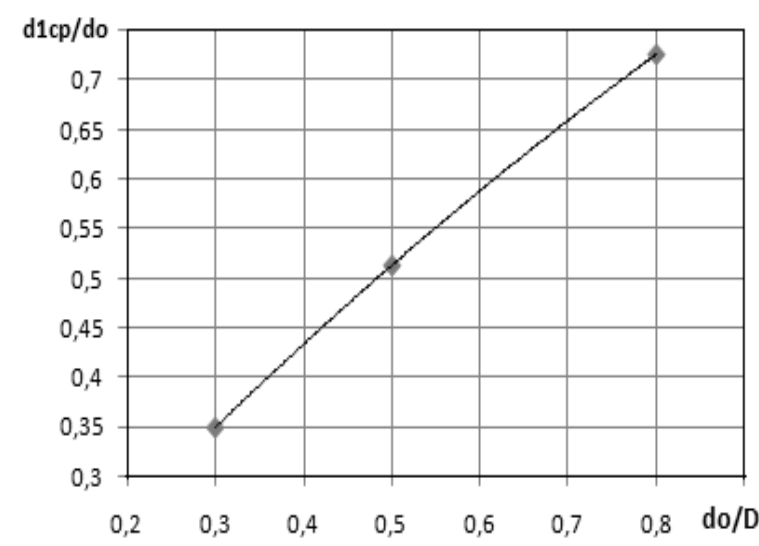

Рисунок 4 - Вплив відносного діаметру отвору заготовки на ступінь заковування отвору при обтисненні на 20 \% вирізними бойками

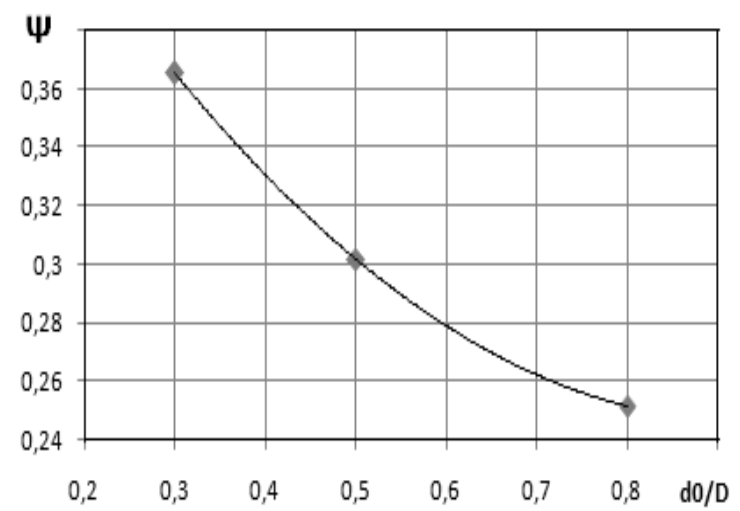

Рисунок 5 - Вплив відносного діаметра отвору заготовки на відносне подовження заготовки при обтисненні на $20 \%$ вирізними бойками

Було встановлено, що зі збільшенням діаметра отвору вихідної заготовки (зменшенням товщини стінки вихідної заготовки) збільшується кінцевий діаметр отвору поковки. Однак при цьому відбувається зменшення відносного подовження заготовки (ж) (рис. 5).

У зв'язку 3 цим було додатково встановлено вплив відносного діаметра заготовки на відносну товщину стінки (рис. 6) після обтискання на 20\%. При співвідношенні d0/D=0,55 спостерігається максимальне значення інтенсивності потовщення стінки (рис. 6).

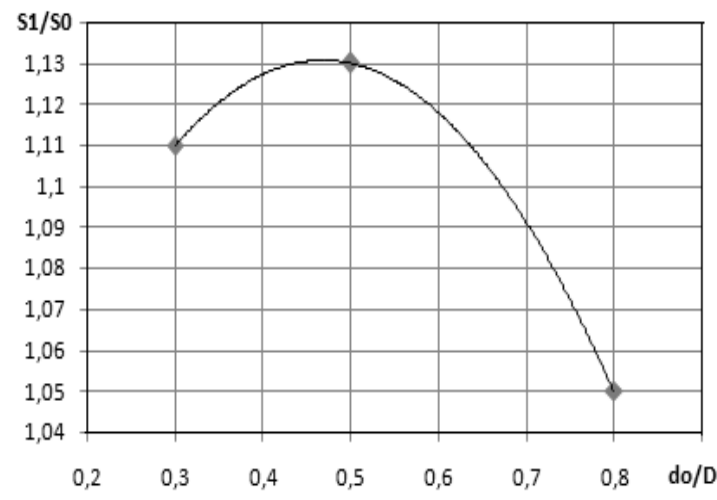

Рисунок 6 - Відносна товщина стінки поковки в залежності від відносного діаметру отвору при обтисненні на 20 \% вирізними бойками
Отримані результати пояснюються різними об'ємами заготовок при різних діаметрах отвору (товщинах стінки). При збільшенні діаметра отвору (тонкої стінці) заковування отвору і подовження менше (див. рис. 4; 5), ніж при зменшенні діаметра отвору (товстої стінці). Це пояснюється різною величиною об'єму заготовки, який деформується. Тому оцінка подовження заготовок з різними об'ємами $\epsilon$ неадекватною, а ступінь зміни діаметра отвору заготовки не враховує інтенсивність подовження для різних стінок при постійної деформації.

Оцінку заковування отвору заготовки, для різних діаметрів отворів, необхідно проводити на підставі показника, який буде враховувати інтенсивність зменшення діаметру отвору - інтенсивність подовження, який визначається відношенням зміни площі кінцевої поковки і початкової заготовки до обтисненої площі поперечного перерізу заготовки

$$
f=\frac{F_{0}-F_{K}}{F_{\text {обт }}}=\frac{\left(D^{2}-d_{0}^{2}\right)-\left(D_{K}^{2}-d_{1}^{2}\right)}{D^{2}-D_{K}^{2}},
$$

де $\mathrm{D}, \mathrm{D}_{\mathrm{K}}-$ зовнішній діаметр вихідної та протягнутої заготовки, відповідно; $\mathrm{d}_{0}, \mathrm{~d}_{1}$ - діаметр отвору заготовки та поковки, відповідно.

Запропонований показник показує інтенсивність (швидкість) подовження в залежності від обтискання зовнішнього діаметра заготовки. Іншими словами формула показує частку обтискання площі заготовки, яка йде на збільшення довжини поковки. При $\mathrm{f} \rightarrow 0$, коли площа перетину практично не змінюється подовження заготовки також прагне до нуля. При $\mathrm{f} \rightarrow 1$, коли зміна площі заготовки в процесі кування дорівнює площі обтискання заготовки $\left(F_{0}-\right.$ $\left.F_{K}=F_{\text {обт }}\right)$, все обтискання призводить до збільшення подовження заготовки.

Протягування пустотілих заготовок класичними вирізними бойками не сприяє інтенсивному подовженню заготовки, а навпаки сприяє інтенсивному заковуванню отвору пустотілої заготовки. Збільшення діаметра отвору в пустотілої заготовки сприяє зниженню подовження (рис. 7).

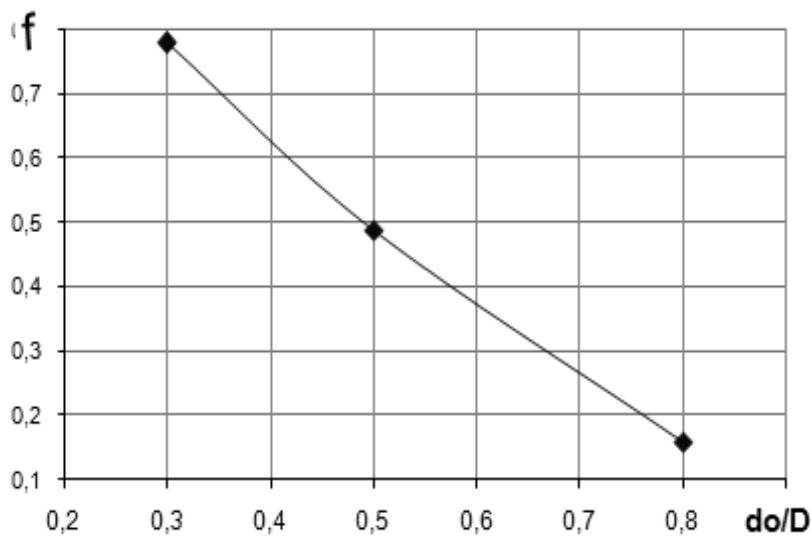

Рисунок 7 - Вплив відносного діаметра отвору заготовки на інтенсивність подовження поковки при обтисненні на $20 \%$ вирізними бойками 
Це пояснюється тим, що при значних діаметрах отвору (тонкої стінці) металу «легше» плинути в радіальному напрямку, ніж в осьовому. У зв'язку з цим необхідно вдосконалювати схему кування пустотілих заготовок без оправки для збільшення інтенсивності подовження металу заготовки, а відповідно, зменшення величини заковування за рахунок зменшення інтенсивності збільшення товщини стінки пустотілої заготовки.

Розроблено новий спосіб протягування труб без використання оправки. Встановлено розподіл температур, деформацій та залежності зміни розмірів внутрішнього діаметру та потовщення стінки трубної заготовки при протягуванні без використання оправки. Одержані результати дозволили визначили раціональні геометричні параметри трубної заготовки до деформування без використання оправки, а також переваги перед існуючими способами протягування пустотілих виробів:

- Удосконалено спосіб виготовлення товстостінних труб з внутрішнім діаметром менш 300 мм (труби надвисокого тиску, штанги бурових установок та ін.). Раніше такі вироби виготовлялись з суцільних заготовок свердленням. Це потребувало значного часу на механобробку та збільшення витрат металу.

- Деформування труб без використання оправки дозволило зменшити кількість підігрівань заготовок за рахунок виключення охолодження, яке притаманне способу протягування на охолоджувальній оправці, що установлюється в отвір трубної заготовки. В результаті зменшується час деформування та витрати енергії на підігрівання заготовки.

- Розроблений спосіб кування без використання ковальської оправки дозволяе не використовувати спеціальних оправок $з$ жароміцної сталі.

- При деформуванні без використання оправки змінюється розподіл температур та деформацій трубної заготовки. В результаті при обтисканні метал тече не тільки у поздовжньому напрямку, але й поперек осі поковки.

- Розроблено параметр подовження трубної заготовки, що визначає швидкість подовження трубної заготовки над швидкістю потовщення стінки, який дозволяє оцінити формозмінення заготовки при протягуванні без використання оправки.

До обмежень розробленого способу деформування товстостінних труб слід віднести:

- Деформування без використання оправки призводить до течії металу поперек осі труби, що приводить до подовшення стінки та ускладнення керованості формозміни заготовки. Це потребує точно витримувати задані режими деформування.

- Відсутність внутрішньої оправки потребує до збільшення припуску на внутрішній діаметр труби.

- Запропонований спосіб протягування доцільно застосовувати тільки для виготовлення товстостінних труб.

Встановлені в роботі рекомендації по геометричним параметрам заготовок є значущими науковопрактичними напрацюваннями, які можна використовувати в теорії та технології процесів деформування пустотілих виробів без використання оправки.
Практичним аспектом використання результатів моделювання є вдосконалення техпроцесу протягування труб з внутрішнім діаметром <300мм, коли застосування оправки неможливе.

ВИСНОВКИ. Встановлено, що перепад температур в об'ємі поковки не перевищує за границі гарячої обробки тиском. Середній перепад температури в об'ємі поковки становить $350^{\circ} \mathrm{C}$. В результаті кількість нагрівань при остаточному протягуванні у порівнянні з базовою технологією кування знизилась 32 до 1 нагріву.

Встановлено, що при збільшенні внутрішнього діаметру заготовки подовження збільшується та зменшується заковування отвору. Загальна залежність змодельованих процесів деформування - подовження відбувається незначно при різних рівнях деформування для фіксованих розмірів трубної заготовки. Це дозволило встановити рекомендовану подачу і зменшення заковування внутрішнього діаметру. Раціональна відносна подача для інтенсивної витяжки пустотілої заготовки складає 5...15\% від діаметру заготовки.

\section{ЛІТЕРАТУРА}

1. Baoguang S., Xiuhong K., Dianzhong L. A novel technique for reducing macrosegregation in heavy steel ingots / S. Baoguang. J. Materials Processing Technology. 2010. № 210. P. 703-711.

2. Zhu Baiqing, Lu Haixing, Tong Yifei, Li Dongbo, Xia Yong. Research on Charging Combination Based on Batch Weight Fit Rule for Energy Saving in Forging. Mathematical Problems in Engineering. 2015. - Article ID 531756, 9 pages. http://dx.doi.org/10.1155/2015/531756.

3. Kun Chen, Yitao Yang, Guangjie Shao. Strain function analysis method for void closure in the forging process of large sized steel ingot. Computational Materials Science. 2012. № 51. P. 72-77.

4. Wu Y., Xianghuai Dong, Qiong Yu. Upper bound analysis of axial metal flow inhomogeneity in radial forging process. International Journal of Mechanical Sciences. 2015. № 93. P. 102-110.

5. Sizek H. W. Radial Forging. Metalworking : Bulk Forming. 2005. P. 172-178.

6. Ghaei A., Movahhedy M.R., Karimi Taheri A. Finite element modelling simulation of radial forging of tubes without mandrel. Materials \& Design. 2008. № 29. P. 867-872.

7. Fan L., Wang Z., Wang H. 3D finite element modeling and analysis of radial forging processes. Journal of Manufacturing Processes. 2014. № 16. P. 329-334.

8. Markov O. E., Oleshko M. V., Mishina V. I. Development of Energy-saving Technological Process of Shafts Forging Weighting More Than 100 Tons without Ingot Upsetting. Metalurgical and Mining

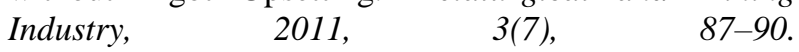
http://www.metaljournal.com.ua/assets/Uploads/attach ments/87Markov.pdf

9. Дефектоутворення на обичайках з одностороннім уступом під час розкочування профільованим східчастим інструментом / М. С. Косілов, О. В. Герасименко, О. С. Марков, А. С. Хващинсь- 
кий, О. О. Шаповал. Вісник Кременчуиьького національного університету імені Михайла Остроградського. Кременчук: КрНУ, 2018. Вип. №2(109). С. 4147. DOI: http://dx.doi.org/10.30929/19950519.2018.2.p1.41-47
10. Дослідження формозміни та деформованого стану східчастих заготовок під час розкочування профільованим бойком / М. С.Косілов, О. С. Марков, О. В. Герасименко, С. В. Інчаков. // Вісник Кременчуцького національного університету імені Михайла Остроградського. 2017. Вип. №5. С. 82-88.

\section{COMPUTERIZED SIMULATION OF THE FORGING PROCESSES OF THICK-WALL PIPES WITHOUT MANDREL}

\section{O. Markov, O. Gerasymenko}

Donbas State Machine -Building Academy

vul. Akademicheskaya, 72, Kramatorsk, 84313, Ukraine.

E-mail: oleg.markov.omd@gmail.com; mto@dgma.donetsk.ua

Purpose. The article aims at developing of a new method for pulling thick-walled pipes, which consists in forging a hollow billet without using of forging mandrel. A technique for conducting theoretical by finite element method (FEM) studies has been developed. Methodology. The technique is intended to determine the thermal, deformed state and the shaping of the workpiece when forging pipes without the use of a mandrel. The variable parameters were the inner diameter of the hollow billet, which varied in the range of $0.30 ; 0.55 ; 0.80$. On the basis of the finite element modeling, the following were established: temperature distribution and intensity of logarithmic deformations in the volume of the pipe after pulling without the use of a mandrel. Results. The diameter of the hole in the pipe, which is formed during broaching by this method, was determined. The dependences of the intensity of elongation and thickening of the pipe wall were established. Originality. A special indicator has been developed to evaluate an intensity of the pipe elongation. It was determined that with an increase in the internal diameter, the elongation of the pipe increases and the intensity of the forging of the hole decreases. The general dependence of the simulated broaching patterns is that the magnitude of the hollow billet elongation does not change significantly for different degrees of reduction at constant relative pipe sizes. Practical value. This allowed us to establish the recommended feed to increase the elongation of the hollow forging and reduce the degree of closure of the hole. Rational submission should be $(0.05 \ldots 0.15) \mathrm{D}$. The obtained results allowed to determine the rational geometrical parameters of the pipe workpieces to the deformation without using of the forging mandrel. According to the simulation results by FEM, it was established that the drawing of tubular blanks without using of the forging mandrel is possible. This method extends the possibilities of the technological processes of the billets manufacture by forging. The practical aspect of simulation results using is to improve the process of drawing pipes with an internal diameter less than $300 \mathrm{~mm}$ when the using of the forging mandrel is not possible. References 10 , figures 5 .

Key words: thick-walled pipe, broach without mandrel, forging, shackling of a hole, lengthening intensity.

\section{REFERENCES}

1. Baoguang, S., Xiuhong, K., Dianzhong, L. A (2010), Novel technique for reducing macrosegregation in heavy steel ingots, J.Materials Processing Technology, № 210, p. 703-711.

2. Baiqing, L., Haixing, T., Yifei, L., Dongbo, X. Y. (2015), Research on Charging Combination Based on Batch Weight Fit Rule for Energy Saving in Forging, Mathematical Problems in Engineering, http://dx.doi.org/10.1155/2015/531756.

3. Kun, Ch., Yitao, Y., Guangjie, Sh. (2012), Strain function analysis method for void closure in the forging process of large sized steel ingot, Computational Materials Science, № 51, p. 72-77.

4. Wu, Y., Xianghuai, D., Qiong, Yu (2015), Upper bound analysis of axial metal flow inhomogeneity in radial forging process, International Journal of Mechanical Sciences, № 93, p. 102-110.

5. Sizek, H. W. (2005), Radial Forging, Metalworking : Bulk Forming, p. 172-178.

6. Ghaei, A., Movahhedy, M. R., Karimi, Taheri A. (2008), Finite element modelling simulation of radial forging of tubes without mandrel, Materials \& Design, № 29, p. 867-872.
7. Fan, L., Wang, Z., Wang, H. (2014), 3D finite element modeling and analysis of radial forging processes, Journal of Manufacturing Processes, № 16, p. 329-334.

8. Markov, O. E., Oleshko, M. V., Mishina, V. I. (2011), Development of Energy-saving Technological Process of Shafts Forging Weighting More Than 100 Tons without Ingot Upsetting. Metalurgical and Mining Industry, Vol. 3(7), p. 87-90. http://www.metaljournal.com.ua/assets/Uploads/attach ments/87Markov.pdf

9. Kosilov, M. S., Gerasimenko, O. V., Markov, O. E., Hvaschinskiy, A. S., Shapoval, O. O. (2018), Defect formation in shells with one-way ledge during rolling with a profiled stepping tool, Transactions of Kremenchuk Mykhailo Ostrohradskyi National University, Vol. 2(109), pp. 41-47, DOI: http://dx.doi.org/10.30929/1995-0519.2018.2.p1.41-47

10. Kosilov, M. S., Markov, O. E., Gerasimenko, O. V., Inchakov, E. V. (2017), Investigation of deformed state of stepped billets during rolling with profiled die, Transactions of Kremenchuk Mykhailo Ostrohradskyi National University, Vol.5, p. 82-88. 